\title{
COMBINED SHEAR-FLEXURAL VERIFICATION OF IN PLANE LOADED REINFORCED AND UNREINFORCED MASONRY WALLS
}

\author{
ANDREA BENEDETTI ${ }^{* 1}$, MIRCO TAROZZI ${ }^{1}$ AND LORENZO BENEDETTI ${ }^{2}$ \\ ${ }^{1}$ DICAM Department \\ Università degli Studi di Bologna \\ 2, Viale Risorgimento, 40136 Bologna, Italy \\ e-mail: andrea.benedetti@unibo.it, www.unibo.it/en (*corresponding author) \\ ${ }^{2}$ STI DESL, Ecole Polytechnique Fédéral Lausanne \\ ELL 166 Station 11 \\ CH-1015 Lausanne, Switzerland \\ Web page: https://people.epfl.ch/lorenzo.benedetti?lang=en
}

Keywords: Masonry panel, in-plane loading, shear-flexural verification, reinforcement design

Abstract. The safety verification of in-plane loaded masonry panels requires the evaluation of at least three different collapse conditions connected with overturning, shear sliding, and shear - compression failure at the panels' toe. In reinforced panels, the resisting models should even take into consideration the presence of localized or distributed reinforcement.

In general, the masonry is considered a Mohr-Coulomb type material not resisting tension and plastic in compression, while reinforcement is a brittle elastic material resisting tensile forces only [1].

The ultimate limit state is however linked with a given subset of compressed material inside the panel area. The compressed sections are therefore varying inside the panel as a function of the applied load. The collapse occurs in shear or overturning when one peculiar compressed section reduces to its minimum [2].

By equating the capacity in shear and overturning it is possible to derive an explicit statement of the minimum length of the compressed section which will be activated by a simultaneous failure in shear and overturning. A simple inequality is detecting the real failure mode and this allows directly computing the failure load resultant.

The procedure is very fast and can deal even with localized or distributed reinforcement layers such as fiber strips or mesh reinforced mortars.

Some examples of panels discussed in the literature show the effectiveness of the proposed verification procedure.

\section{INTRODUCTION}

As is well-known masonry panels under in-plane loading can exhibit several collapse forms 
according to the combination of geometry, restraint, axial and shear forces acting on it.

In particular, due to the low tensile capacity of masonry materials, small axial compression forces lead to moderate shear capacities, mainly linked to the cohesion of the material.

If the horizontal displacement demand increases, cracks running on the mortar joints will appear in the masonry panel, reducing thus the length of the compressed zone along the height of the panel. In the cracked condition, the shear is carried on by the compressed area only, producing so a mixed compression-shear state on the masonry. At the shear peak value, the panel can collapse alternately with rocking failure until overturning, or with sliding failure with progressive crack opening.

Collapse by overturning is typical of slender panels under low or moderate axial forces, while shear sliding is typical of very squat walls. When the axial force is very high or the compressive masonry strength is very low, the probability that the panel will fail with shear crushing of the compressed toe increases considerably. In this case, inclined diagonal cracks splitting the bricks arise on the panels.

In this paper, the problem of mixed shear-rocking failure is solved by determining the compressed zone length that makes the shear producing overturning and sliding the same. A closed formula allows computing the ending geometry of stable behavior. Namely, after this point, by decreasing the size of the compressed zone even the shear has to reduce its value in a softening branch. The limit value that results in a shear-crushing of the toe is even expressed in terms of the Mohr-Coulomb failure criterion.

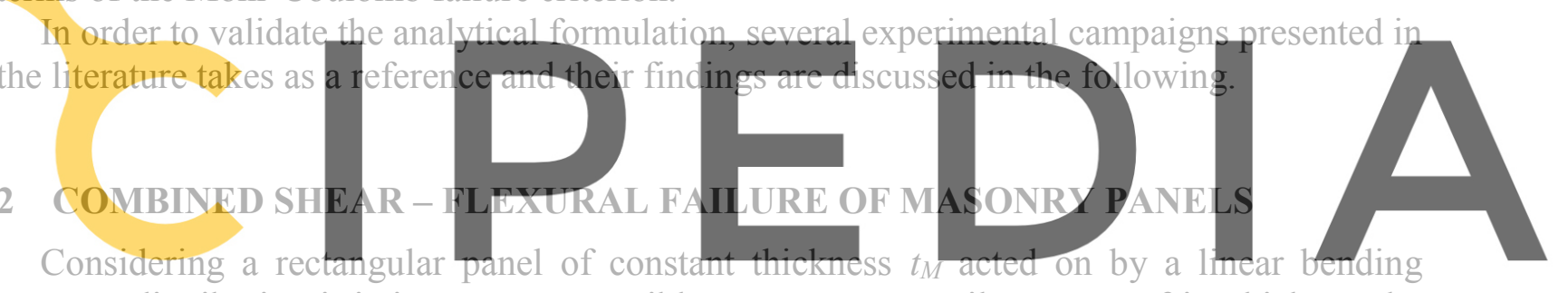

moment distribution it is in any case possible to extract a cantilever part of it which can be

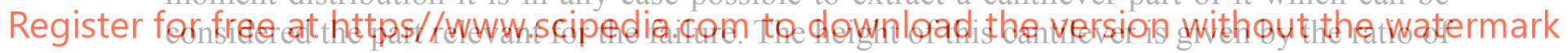

the largest bending moment $M_{S}$ to the shear force $V_{S}$ and is equivalent to a shear arm $a_{v}$ :

$$
a_{V}=\frac{M_{S}}{V_{S}}
$$

As a consequence of the limited tensile resistance of the masonry texture and beyond a certain shear force, the base section of the cantilever begins to crack, and therefore the equilibrium is guaranteed by the eccentricity of the stress resultant acting on the contact area.

The verification of this incipient failure situation is in general carried out by using different formulas for the possible collapse modes: flexural overturning, shear sliding and shearcompression crushing (according to the Mohr-Coulomb criterion, see [1]).

$$
\begin{aligned}
& V_{R, f l}=\frac{N_{S} L}{2 a_{V}}\left(1-\frac{N_{S}}{\kappa N_{P}}\right) \\
& V_{R, s h}=\mu N_{S}+\beta t_{M} f_{M V 0}
\end{aligned}
$$




$$
V_{R, M C}=\beta t_{M} f_{M V 0} \sqrt{\left(1+\frac{\sigma_{0}}{f_{M t}}\right) \cdot\left(1-\frac{\sigma_{0}}{f_{M c}}\right)}
$$

In the given formulas $N_{S}$ is the axial force in the panel, $L$ and $t$ are the length and the thickness of the panel' section, $f_{M c}$ and $f_{M t}$ are respectively the compressive and tensile strength of the masonry material, $\beta$ is the length of the compressed area in the base section, $\kappa$ and $\mu$ are the ductility and friction coefficients. The other variables are as follows:

$$
N_{P}=L t_{M} f_{M c}, f_{M V 0}=\frac{f_{M t} \cdot f_{M c}}{f_{M t}+f_{M c}}, \sigma_{0}=\frac{N_{S}}{\beta t_{M}} .
$$

It is to note that the shear-compression failure formula derived in agreement with the MohrCoulomb criterion is very similar to the Turnsek-Cacovic formula if the axial stress is not very high:

$$
\tau_{R, M C}=\tau_{R, T C} \cdot \sqrt{\left(1-\frac{\sigma_{0}}{f_{M C}}\right)}
$$

The resisting shear stress is obviously the minimum among the three formulas (2).

Since masonry in compression can be considered an elastic perfectly plastic material [3], the stress distribution at the panel's base is a consequence of the linear strain distribution. By assuming that the ductility $D$ of the material is described by the ratio of the ultinate strain to the limit elastic one compressed area and the

If the cantilever is length of the contact are
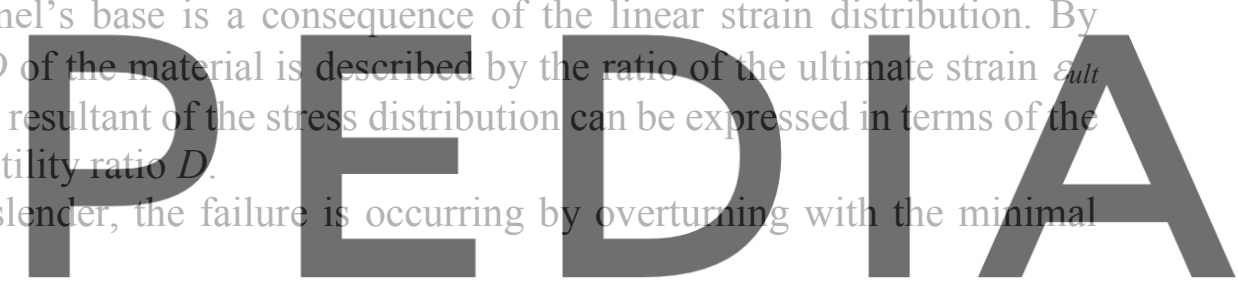

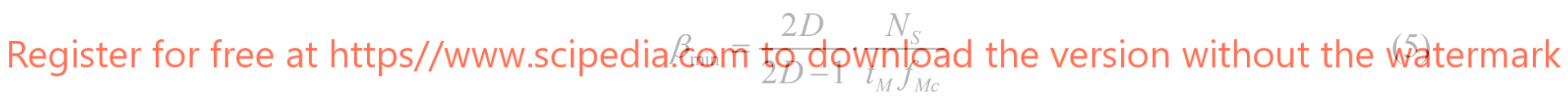

If the cantilever is sufficiently squat, the failure is occurring by shear with a compressed zone larger than the minimal one. The value of the compressed length at failure can be computed by equating the shear force producing sliding with the one producing overturning:

$$
\begin{gathered}
\frac{M_{R, f l}}{a_{V}}=\frac{N_{S}}{a_{V}}\left(\frac{L}{2}-\frac{\bar{\beta}}{n}\right)=\mu N_{S}+\bar{\beta} t_{M} f_{M V 0}=V_{R, s h} \\
\beta_{\lim }=\bar{\beta}=\frac{n}{2} \frac{N_{S}\left(L-2 \mu a_{V}\right)}{N_{S}+n a_{V} t_{M} f_{M V 0}} \geq \beta_{\min }
\end{gathered}
$$

The value of the parameter $n$ is defining the adimensional distance of the stress resultant force from the edge of the panel:

$$
n=\frac{1+3 D(D-1)}{3 D(2 D-1)}
$$


Since the deflection of the cantilever can only increase if the shear is increasing and the compressed length is decreasing (in order to guarantee the rotational equilibrium), the limit $\bar{\beta}$ defines even the limit stable displacement of the panel. If the shear - displacement curve of the panel is known, the curve must be cut at $V_{R, \lim }$ given by $\beta_{\text {lim. }}$.

Many procedures exist that can allow plotting the shear - displacement curve up to panel overturning (see among the others $[4,5]$ ). One very simple procedure allowing for wellapproximated shear displacement curves is the use of hyperbolic functions. As is usual in geotechnics, only two parameters are necessary to build up an effective relationship:

$$
V(\delta)=\delta \cdot\left(\frac{1}{K_{0}}+\frac{\delta}{V_{\lim }}\right)^{-1}
$$

In which $K_{0}$ is the initial stiffness of the panel and $V_{\text {lim }}$ the maximum resisting shear when the displacement tends toward infinity.

If masonry panels are concern, the initial stiffness is computed from the geometry and the material properties of the panel. The limit shear is computed from the largest panel eccentricity attained at the overturning.

$$
\frac{1}{K_{0}}=\frac{12 H^{3}}{c E_{M} L^{3} t}+\frac{H}{G_{M} L t}
$$

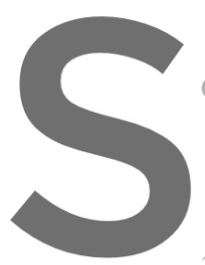

Where $E_{M}$ and $G_{M}$ describing the end rotational resti Once $V_{R, s h}<V_{\text {lim }}$ is $\mathrm{k}$

3
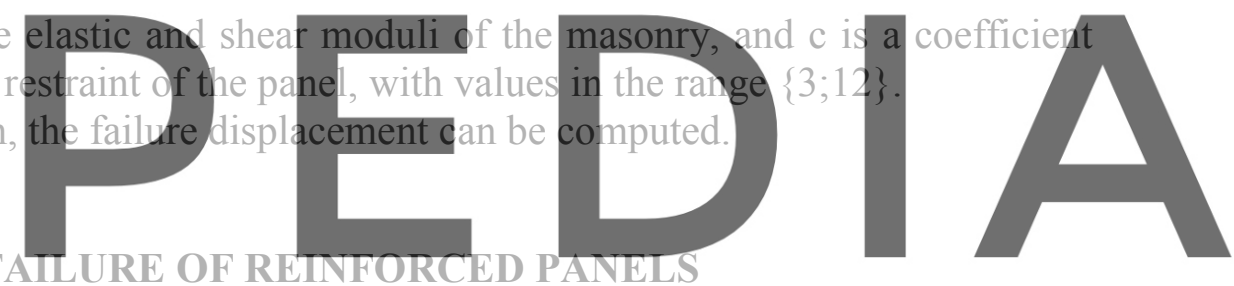

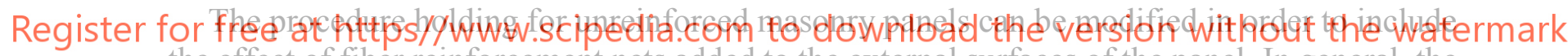

the effect of fiber reinforcement nets added to the external surfaces of the panel. In general, the flexural reinforcement of masonry elements is carried out by adding fiber strips along the vertical edges of the walls or by using fiber cross braces on the wall faces. The shear reinforcement of the panel instead, is best suited by using mortar coatings and fiber meshes on the faces or by using near-surface mounted bars (NSM) resting on the mortar courses.

The flexural reinforcement is based on the introduction of some tensile resisting force that can carry on a bending moment summing up with the one resisted by the masonry alone. On the contrary, shear reinforcement is mainly thought for increasing the shear capacity of the masonry material.

In what follows a reinforced panel is considered, in which the four vertical edges are equipped with unidirectional strips of fibers externally bonded to the bricks (EBR). Moreover, the panel is reinforced in shear by means of two external thin layers of high strength mortar reinforced with glass fiber meshes.

The CNR-UNI documents 200 and 213 [6,7] contain the basic theoretical formulation for the strength evaluation of fiber reinforcement systems in which the bonding agent is high strength mortar. A homogenization strategy is presented in [1] able to deal with mortar coatings reinforced with fiber meshes. 
Considering the panel presented in figure 1 the aim is the definition of a suitable modification for the formulas presented in the previous section.

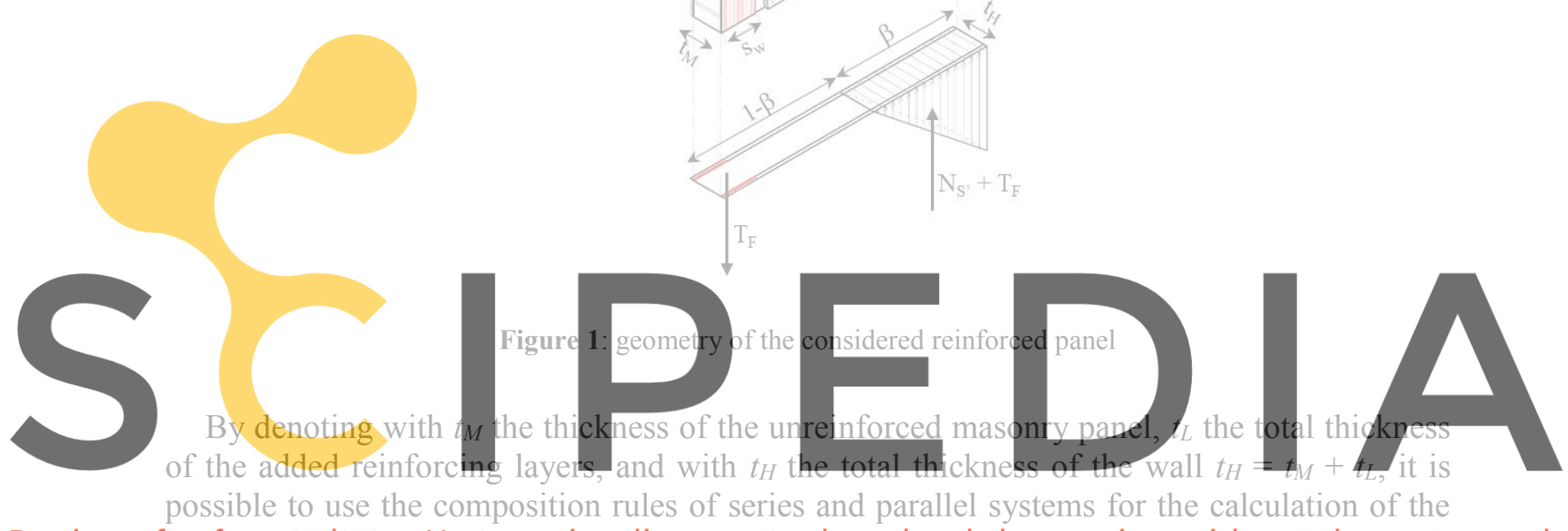

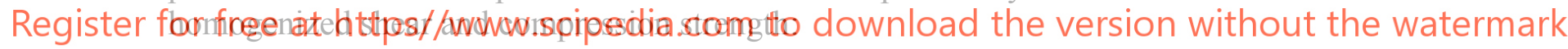

$$
f_{H V 0}=\frac{f_{M V 0} t_{M}+f_{L V 0} t_{L}}{t_{M}+t_{L}}, f_{H c}=\frac{f_{M c} t_{M}+f_{L c} t_{L}}{t_{M}+t_{L}}
$$

Where $f_{L c}$ and $f_{L V 0}$ are the compressive and shear strength of the reinforcing coatings. The homogenization through the volumetric ratios is possible if the connection between the masonry panel and the reinforced coatings is sufficiently ductile in leading to the full yielding of both materials.

If the flexural capacity of the panel is not sufficient for the rotational equilibrium, added reinforcement strips on the edges can supply the missing resisting moments. By using formulas for EBR or NSM the axial strength $T_{F}$ of the reinforcement can be computed:

$$
T_{F}=\sqrt{2 E_{F} G_{F} A_{F} s_{w}}
$$

In formula (10) $E_{F}$ is the reinforcement elastic modulus, $G_{F}$ is the fracture energy of the interface, $A_{F}$ is the reinforcement area and $s_{w}$ is the breadth of the bonding surface [6].

Once the strength of the flexural reinforcement is defined, the formulas $(5,6)$ can be modified in order to include the effect of the added strength: 


$$
\begin{gathered}
\lambda_{\min }=\frac{2 D}{2 D-1} \frac{\left(N_{S}+T_{F}\right)}{t_{H} f_{H c}} \\
\bar{\lambda}=\frac{n}{2} \frac{N_{S} L+2 T_{F} d-2 \mu a_{V}\left(N_{S}+T_{F}\right)}{N_{S}+T_{F}+n a_{V} t_{H} f_{H V 0}}
\end{gathered}
$$

Where $d$ is the distance of the reinforcement axis to the most compressed fiber.

If $\bar{\lambda}$ is larger than $\lambda_{\min }$ the limit shear force is easily computed as:

$$
V_{H, s h}=\mu\left(N_{S}+T_{F}\right)+\bar{\lambda} t_{H} f_{H V 0}
$$

Alternately, if $\lambda_{\min }$ is the smallest length, the limit shear force is computed as:

$$
V_{H, f l}=\frac{M_{H, f l}}{a_{V}}=\frac{1}{a_{V}}\left[N_{S}\left(\frac{L}{2}-\frac{\lambda_{\min }}{2}\right)+T_{F}\left(d-\frac{\lambda_{\text {min }}}{2}\right)\right]
$$

\section{VERIFICATION OF THE PROPOSED FORMULA}

The analysis previously defined is applied to a set of eight brick masonry walls tested by Churilov et Al. [8]. The height of the walls was fixed to $1820 \mathrm{~mm}$, while two different lengths respectively equal to $1420 \mathrm{~mm}$ and $2820 \mathrm{~mm}$ were chosen investigating the effect of the aspect ratio on the lateral capacit of the in-plane behavior specimens was split in walls. The walls of on jacketing technique.
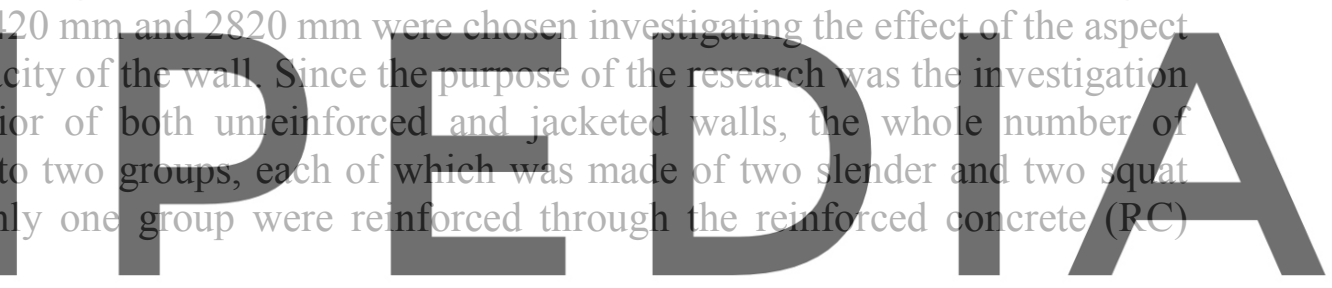

The reinforcement was applied to the external faces of the panels by executing transversal

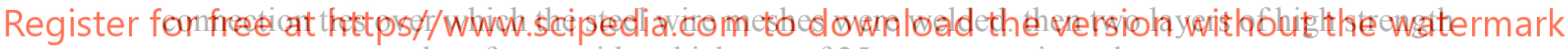
mortar were poured on forms with a thickness of $25 \mathrm{~mm}$ approximately.

Table 1 collects the thicknesses $t$ of the masonry components, their elastic modulus $\mathrm{E}$ and their tensile and compressive strength, $f_{t}$ and $f_{c}$, respectively. Concerning brick units, the cylindrical compressive strength was computed as 0.83 times the cubic one, while their tensile strength was evaluated from the flexural tensile strength obtained experimentally.

Elastic moduli of mortar and bricks were estimated starting from their compressive strengths [3]. All these properties were used in this paper to compute the mechanical properties of the masonry walls validating the proposed formulas.

The presented experiments considered very squat panels under a very high axial load and repeated alternated increasing displacement cycles. Therefore they constitute a very sharp reference for testing the prediction capability of formulas dealing with shear-compression failure of masonry panels. 
Table 1: Geometrical and mechanical properties of the materials.

\begin{tabular}{ccccc}
\hline & $\begin{array}{c}t \\
{[\mathrm{~mm}]}\end{array}$ & $\begin{array}{c}f_{c} \\
{[\mathrm{MPa}]}\end{array}$ & $\begin{array}{c}f_{t} \\
{[\mathrm{MPa}]}\end{array}$ & $\begin{array}{c}E \\
{[\mathrm{MPa}]}\end{array}$ \\
\hline Brick & 65 & 13.6 & 1.8 & 6800 \\
Lime Mortar & 10 & 0.6 & 0.1 & 300 \\
Concrete & 25 & 22.7 & 3.6 & 20000 \\
Steel Wires & $\Phi 4.2 / 10$ & 450 & 450 & 200000 \\
\hline
\end{tabular}

In Figure 2 some pictures of the failed panels are presented. The cracking pattern shown by the panels highlights a shear sliding failure under high compressive stress with very large contact zones at the two panel ends.

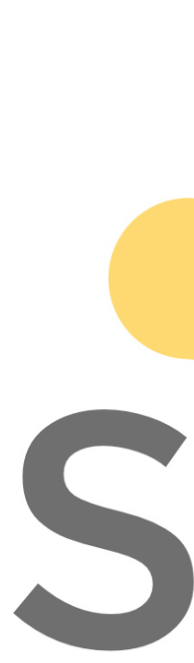

$-\mathrm{H}$ $+\mathrm{H}$
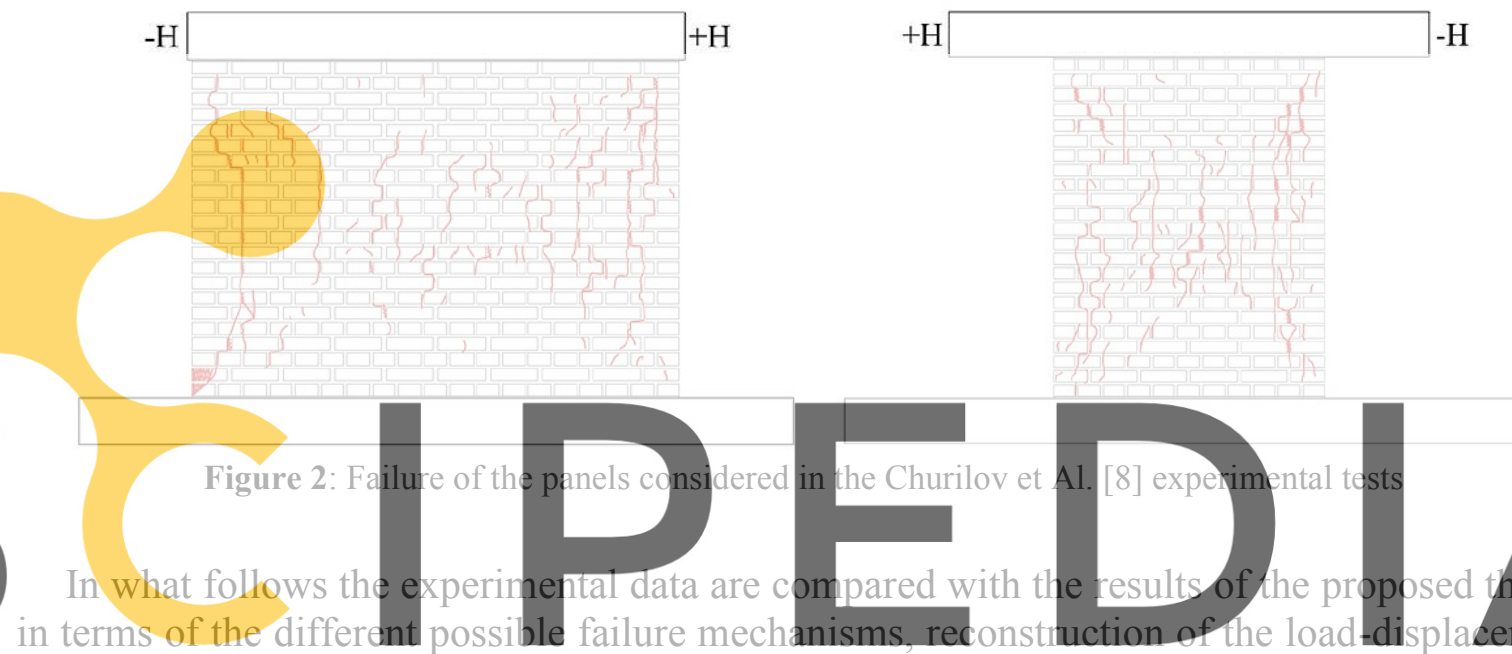

curve and evaluation of the limit displacement at failure. The shear forces $V_{i}$ are computed

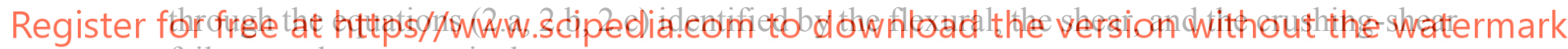
failure modes, respectively.

Table 2 presents the comparison of the computed shear forces with the peak forces of the experimental tests of Churilov et Al. [8]. Concerning the displacements, Table 3 collects the maximum displacements $\delta_{\text {ult }}$ and the percentage drift $\delta \%$ measured in the experimental campaign, compared with the displacements associated with the maximum shear force acting on the wall.

Since the original tests were performed under cyclic loading, two lines described the behavior of the masonry panel along the two opposite directions. For the sake of completeness, both the positive and the negative load-displacement branches were plotted and taken under consideration for the error computation. The maximum analytical displacement $\delta \mathrm{V}$,max provided by the Eq. (8) is the displacement associated with the maximum shear capacity of the wall, assumed as the minimum value among the shears $V_{1}, V_{2}, V_{3}$ collected in Table 2. 
Table 2: Lateral load capacity of URM and SM masonry panels computed for each failure mechanism and under the application of the axial load N.

\begin{tabular}{ccccccccc}
\hline $\begin{array}{c}\text { Units } \\
{[\mathrm{kN}]}\end{array}$ & URM1 & URM2 & URM3 & URM4 & SM1 & SM2 & SM3 & SM4 \\
\hline $\mathrm{N}$ & 630.00 & 365.00 & 315.00 & 182.50 & 630.00 & 365.00 & 315.00 & 182.50 \\
$\mathrm{~V}_{1}$ & 310.22 & 168.27 & 179.23 & 92.12 & 614.50 & 311.65 & 414.61 & 229.57 \\
$\mathrm{~V}_{2}$ & 278.72 & 150.02 & 157.18 & 83.02 & 578.90 & 288.65 & 395.41 & 215.27 \\
$\mathrm{~V}_{3}$ & 174.14 & 100.89 & 139.87 & 80.96 & 1056.82 & 612.28 & 854.32 & 494.54 \\
$\mathrm{~V}_{\max }$ & 174.14 & 100.89 & 139.87 & 80.96 & 578.90 & 288.65 & 395.41 & 215.27 \\
$\mathrm{~V}_{\exp }$ & 189.14 & 88.54 & 157.35 & 65.46 & 483.79 & 227.18 & 365.15 & 208.62 \\
$\mathrm{e}_{\mathrm{V}}$ & $9 \%$ & $-12 \%$ & $12 \%$ & $-19 \%$ & $-16 \%$ & $-21 \%$ & $-8 \%$ & $-3 \%$ \\
\hline
\end{tabular}

Table 3: Experimental [8] and analytical displacements provided for the whole bench of specimens.

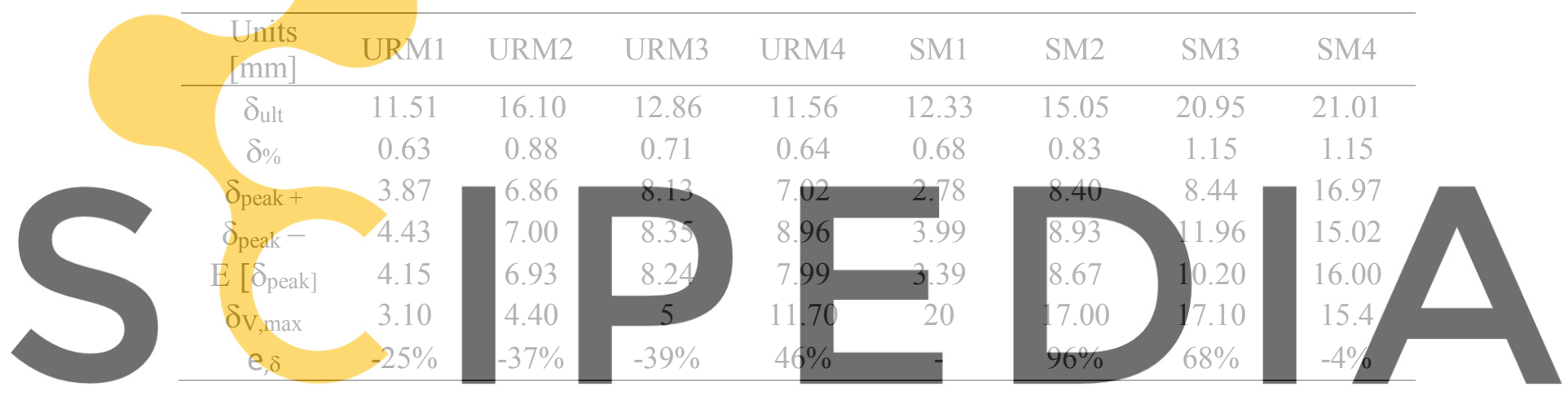

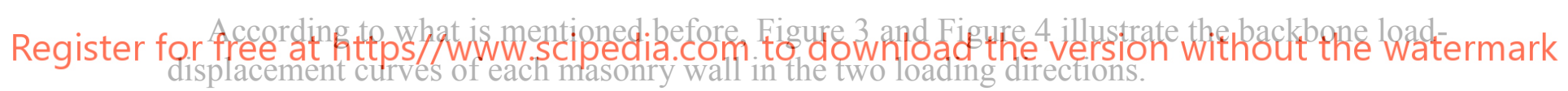

In particular, the solid line describes the lateral capacity of the masonry wall (Eq.8), while red and blue dashed curves are the experimental evolution of the lateral load applied at the top of the wall against the horizontal displacement corresponding to the positive and the negative directions respectively. Two more points are presented in the plots, namely, the triangle identifies the maximum analytical lateral load resisted by the wall, while the circle represents the theoretical maximum displacement given by the existing standards.

The maximum displacements considered by Italian and European standards value are defined as $0.4 \%$ and $0.8 \%$ of the total height of the panel. Specifically, the first value is associated with the shear-type failure, whereas the other one describes the limit displacement in case of panel overturning.

By observing previous tables and figures, it is very clear that the proposed formula is able to appreciate the maximum value of the lateral load at which the panel fails, even if it is barely accurate only in terms of displacements. 

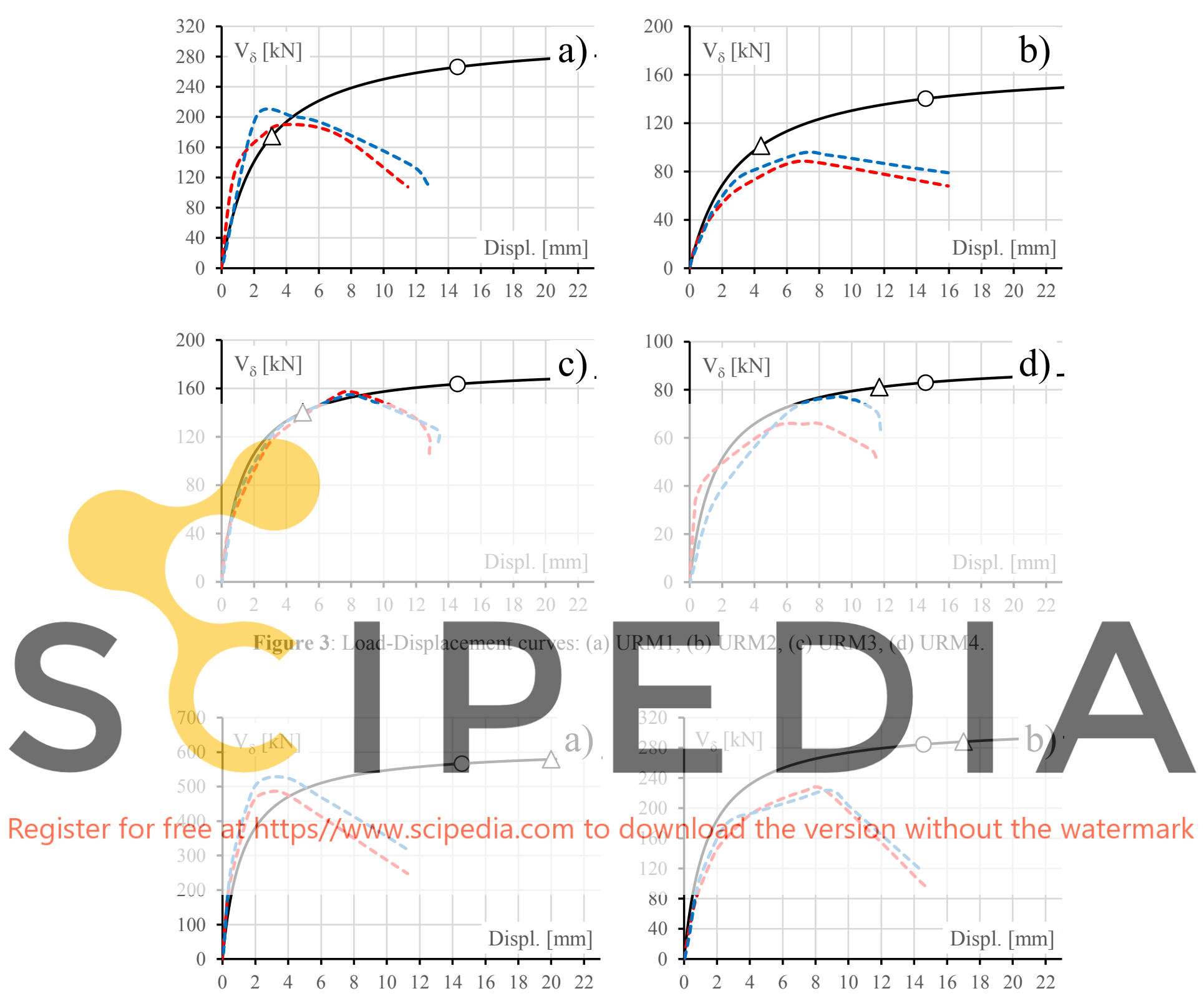

Register for free at/https/Awww.scipedia.com to downlqad the version without the watermark
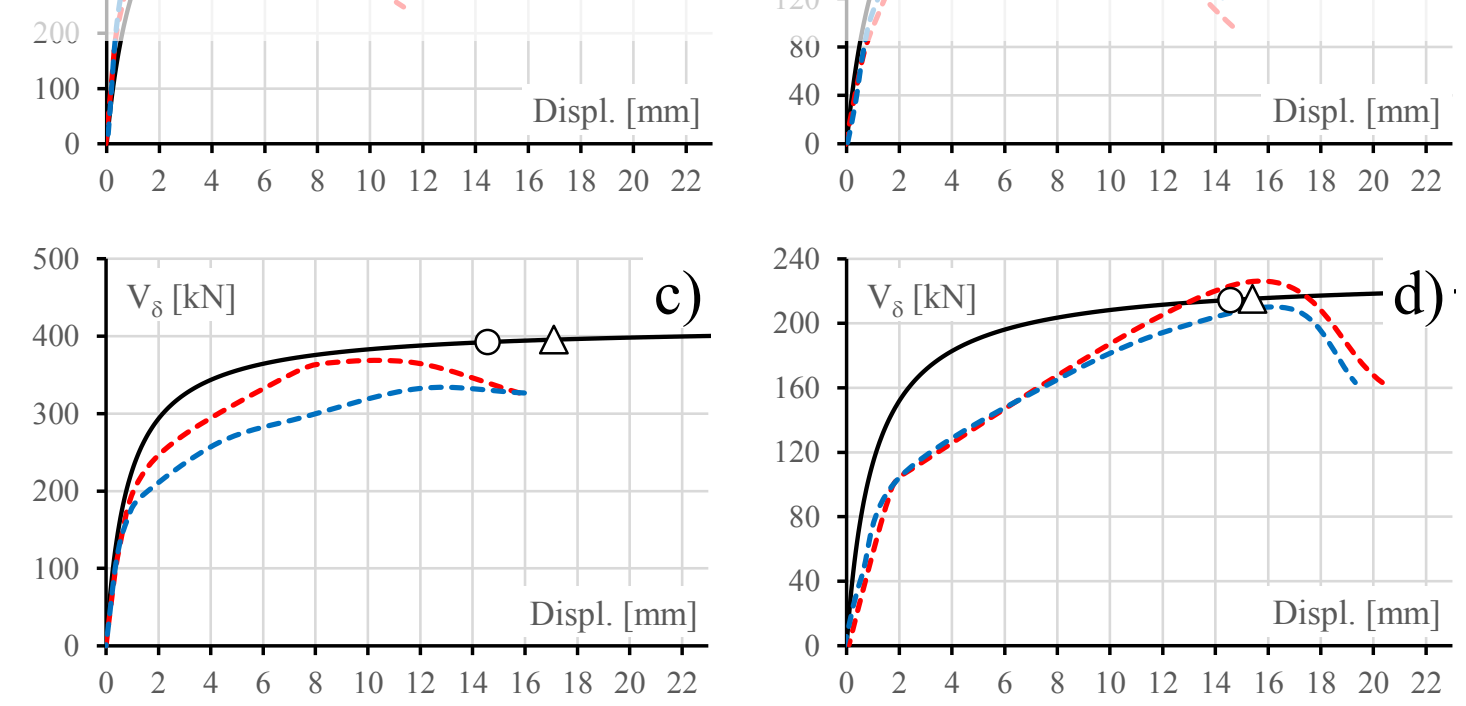

Figure 4: Load-Displacement curves: (a) SM1, (b) SM2, (c) SM3, (d) SM4. 
Concerning lateral stiffnesses collected in Table 4, since the hyperbolic curve needs of the value of initial lateral stiffness $K_{0}$, its value is computed according to Eq.(9) and it is compared with the value provided experimentally in Churilov et Al [8].

It is to mention that the value of stiffness computed analytically was roughly the double of the secant stiffness obtained experimentally, as previously expected. Consequently, it is extremely important to use the initial stiffness in the load path calculations in order to obtain smaller bias in the estimation of the maximum displacement, as is pointed out by the comparison with the experimental data.

Table 4: Tangential and secant lateral stiffnesses of all the specimens, and their ratio.

\begin{tabular}{ccccccccc}
\hline $\begin{array}{c}\text { Units } \\
{[\mathrm{kN} / \mathrm{mm}]}\end{array}$ & URM1 & URM2 & URM3 & URM4 & SM1 & SM2 & SM3 & SM4 \\
\hline $\mathrm{K}_{0}$ & 128.93 & 57.76 & 128.93 & 57.76 & 500.62 & 224.29 & 500.62 & 224.29 \\
$\mathrm{~K}_{\exp }$ & 185.610 & 44.29 & 74.23 & 40.30 & 460.69 & 102.81 & 236.28 & 66.36 \\
$\rho_{\mathrm{K}}[-]$ & 0.69 & 1.30 & 1.74 & 1.43 & 1.09 & 2.18 & 2.12 & 3.38
\end{tabular}

In the paper, the theore panels has been discussed in detail. The limit compression zon of shear and overturnin compression states has been derived in terms

Then, the theoretica coatings of thin FRM tayers, and panels reinforcd ned. The shear
Mohr-Coulonb
extended to pand

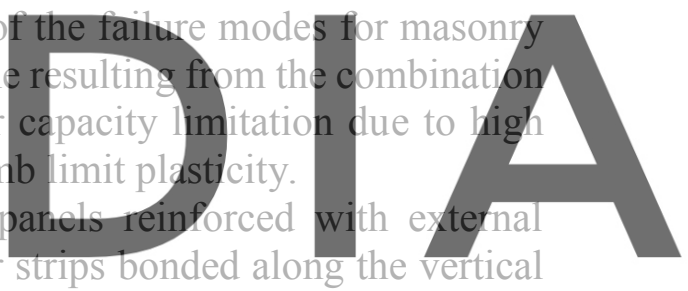
edges

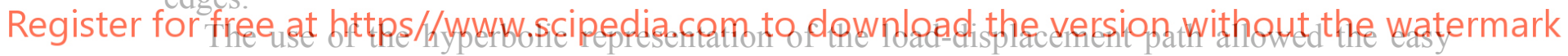
construction of the panel' pushover curves. The parameters needed to build the curves were presented and discussed.

By using some experimental results presented in the literature, the effectiveness of the proposed formulation has been demonstrated. The presented results pointed out the importance of considering shear-crushing failure when the axial force has significant value.

The presented procedure is an easy and fast way for the verification and strengthening design of masonry panels subjected to high compression forces, as in monumental buildings.

\section{REFERENCES}

[1] Benedetti A. In Plane Behaviour of Masonry Walls Reinforced with Mortar Coatings and Fibre Meshes. International Journal of Architectural Heritage (2019) 13-7:1029-1041, DOI: $10.1080 / 15583058.2019 .1618972$

[2] Benedetti A. and Benedetti L. Interaction of shear and flexural collapse modes in the assessment of in-plane capacity of masonry walls. Proc. of the 12th Canadian Masonry Symposium, Vancouver, Canada, June 2nd -5th, 2013. 
[3] Aprile A, Benedetti A, Grassucci F. 2001. Assessment of Cracking and Collapse for Old Brick Masonry Columns. Journal of Structural Engineering, 127:1427-35. DOI:10.1061/(ASCE)0733-9445(2001)127:12(1427).

[4] Benedetti A, Steli E. Analytical models for shear-displacement curves of unreinforced and FRP reinforced masonry panels. Construction and Buildings Materials (2008), 22(3):175185. DOI:10.1016/j.conbuildmat.2006.09.005.

[5] Petry S. and Beyer K. Force-displacement response of in-plane-loaded URM walls with a dominating flexural mode, Earthquake Engng Struct. Dyn. (2015), DOI: $10.1002 /$ eqe. 2597

[6] DT 200-R2. Guide for the Design and Construction of Externally Bonded FRP Systems for Strengthening Existing Structures. CNR, Italy (2014).

[7] DT 215. Istruzioni per la Progettazione, l'Esecuzione ed il Controllo di Interventi di Consolidamento Statico mediante l'utilizzo di Compositi Fibrorinforzati a Matrice Inorganica. CNR, Italy (2019).

[8] Churilov S., and Dumova-Jovanoska E. In-plane shear behaviour of unreinforced and jacketed brick masonry walls. Soil Dynamics and Earthquake Engineering (2013), 50:85105. DOI:10.1016/j.soildn.2013.03.006 